\title{
Discriminant canine index - a novel approach in sex determination
}

\author{
Chennoju Sai Kiran, MDS \\ Pachigolla Ramaswamy, MDS \\ Erva Swathi, MDS \\ Balla Smitha, MDS \\ Shankaran Sudhakar, MDS \\ Department of Oral medicine and Radiology, St. \\ Joseph Dental College, Eluru, India \\ Corresponding author: \\ Chennoju Sai Kiran \\ Department of Oral medicine and Radiology, St. \\ Joseph Dental College \\ Duggirala \\ 534001 Eluru, India \\ E-mail: iamchennojukiran@gmail.com
}

\section{Summary}

Context. Assessment of sex has significant contribution in construction of a physical profile of the decedent along with other parameters like race, stature and age. Sex determination with aid of skeletal remains is difficult procedure when, only a part of the body is obtainable. To solve this difficulty, tooth size standards based on odontometric data can be used in age and sex determination. The present study was undertaken with the objective to evaluate the reliability of sex determination using discriminant canine index (DCI).

Methods. A total of 120 subjects, with healthy periodontium and between the age groups of 15 to 40 years were selected randomly. Subjects with hard tissue abnormalities were excluded from the study. The maximum mesiodistal widths of left mandibular canines were measured intraorally with the help of divider and digital vernier caliper. Data was collected and analyzed statistically.

Results. A significant increase in the mesiodistal width of canines in males $(7.21 \pm 0.45 \mathrm{~mm})$ when compared to females $(6.77 \pm 0.29 \mathrm{~mm})$ was observed. The discriminant canine index (DCl) has identified $68.3 \%$ of males and $76.7 \%$ of females correctly with an overall accuracy rate of $72.5 \%$. Conclusion. The present study indicated that the $\mathrm{DCl}$ can produce reliable results and can be used as an alternative for mandibular canine index (MCI), for sex determination.

Key words: canine tooth, forensic sciences, sex dimorphism, personal identification, gender identity.

\section{Introduction}

The four leading features of biological identity are sex, age, stature, and ancestry background. The forensic anthropologists wish to authenticate these traits for an individual from their skeletal remains. Assessment of sex has significant contribution in construction of a physical profile of the decedent along with other parameters like race, stature and age.

Sex can be assessed with high precision using pelvic and cranial bones. But the demerit of using these bones is that they easily get fragmented which may be major hindrance for assessment of sex. The dentition is considered as an useful adjunct in skeletal sex estimation, particularly since teeth are resistant to postmortem destruction and fragmentation (1). Teeth are the firstrate material for genetic and forensic investigations. Teeth show signs of changes in morphology and they are easily accessible for examination. It is the hardest and chemically most stable structure in the body. They are selectively preserved and fossilized, thereby providing the best proof for evolutionary alteration. Their resilience in the case of fire and bacterial decomposition makes them important for identification in forensic science. Sex determination with aid of skeletal remains is difficult procedure when, only a part of the body is obtainable. To solve this difficulty, tooth size standards based on odontometric data can be used in age and sex determination (2).

"Sexual Dimorphism" refers to differences in size and form between males and females that can be applied to dental identification. In contemporary human populations, males have larger tooth crowns than females. Consequently, tooth size standards based on odontometric investigations could be a reliable method in sex determination when limited skeletal remnants are recovered (3).

Sex determination using dental features is primarily based upon the comparison of tooth dimensions in males and females, or upon the comparison of frequencies of nonmetric dental traits, like Carabelli's trait of upper molars. Mesiodistal and buccolingual diameters of the permanent tooth crown are the two most commonly used and studied features in determining sex on the basis of dental measurements (4).

Tooth sexual dimorphism is often related to body size. In living people today, body size dimorphism averages $10 \%$. Human dental dimorphism is on the order of $2-6 \%$. Canines vary from other teeth with respect to survival and sex dichotomy (1). Of all the teeth in the human dentition, canines are the least frequently extracted teeth (possibly because of the relatively decreased incidence of caries and peri- 
odontal disease). Mandibular canines are considered to be the key teeth for sexual dimorphism. Also, canines are reported to withstand extreme conditions and have been recovered from human remains even in air disasters and hurricanes (5).

Many studies were reported in the literature where mandibular canine index $(\mathrm{MCl})$ was used for sex determination. But very few studies were reported where discriminant analysis was used for gender differentiation. Hence the present study was undertaken with the objective to evaluate the reliability of sex determination using discriminant canine index (DCl).

\section{Materials and methods}

A cross sectional study was planned after the protocol was approved by the institutional committee of research ethics. A total of 120 living subjects were randomly selected comprising of 60 males and 60 females between the age groups of 15 to 40 years.

Subjects with healthy periodontium with no evidence of previous orthodontic treatment were included for the study. Subjects with dental or occlusal abnormalities (rotation, crowding, occlusal disharmony, etc.), physiologic or pathologic wear and tear (e.g. attrition, abrasion, abfraction, erosion) and deleterious oral habits (like bruxism) were excluded for the study.

The maximum mesiodistal widths of left mandibular canines were measured intraorally with the help of divider and digital vernier caliper (Hangzhou Maxwell tools Co. Ltd, Zhejiang, China) with an accuracy of

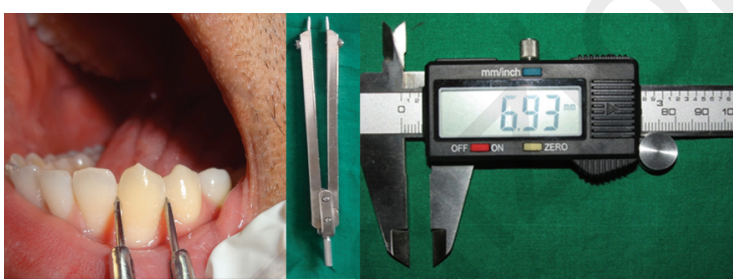

Figure 1. Figure showing measurement of left mandibular canine width clinically. The armamentarium includes divider and vernier callipers. $\pm 0.01 \mathrm{~mm}$ (Fig. 1). The measurements were performed by a single experienced examiner after necessary training. 30 patients were re-evaluated and the measurements were repeated to determine the intraobserver error. The collected data was entered in a spreadsheet (Excel 2007, Microsoft office) and was analyzed using statistical analysis software (SPSS version 16.01, SPSS.inc, Chicago, 1989-2007). Significance was set at 0.05 level $(P<0.05)$. The mean mesiodistal widths of canine were compared in males and females using t-test. Discriminant equation was derived with gender as a classifying variable and mesiodistal widths as independent variables.

\section{Results}

A total of 120 individuals were studied (60 males and 60 females) with an age range of 15 to 36 years. The measurements were made by an experienced oral physician with necessary training. The reproducibility of the measurements was tested by re-evaluating a subset of 30 patients after a period of 3 weeks. The Cohen's kappa value obtained from the analysis was 0.87 which was interpreted to be in almost perfect agreement with the previous measurements.

Measurements included the mesiodistal widths of the left canines at their maximum diameter. The t-test revealed a significant increase in the mesiodistal width of canines in males $(7.21 \pm 0.45 \mathrm{~mm})$ when compared to females $(6.77 \pm 0.29 \mathrm{~mm})$. The Wilks' lambda value obtained in the study was 0.74 (Tab. 1).

The given data were subjected to discriminant analysis using gender as a grouping variable and width of left mandibular canine as an independent variable. The final equation obtained was: $\mathrm{DCl}=(-18.656)+$ $(2.668 \times \mathrm{D})$, where $\mathrm{DCl}$ is discriminant canine index and " $D$ " is mesiodistal width of mandibular canine. A greater $\mathrm{DCl}$ value $(\mathrm{DCl}>0)$ indicates male gender, while a lesser $\mathrm{DCl}$ value $(\mathrm{DCl}<0)$ indicates the probability of female gender. In the present study the discriminant canine index (DCl) has identified $68.3 \%$ of males and $76.7 \%$ of females correctly with an overall accuracy rate of $72.5 \%$ (Tab. 2).

Table 1. Mean measurements of canine in males and females.

\begin{tabular}{llllllll}
\hline & $\begin{array}{l}\text { Gender } \\
\text { of the patient }\end{array}$ & $\mathrm{N}$ & Mean & $\begin{array}{l}\text { Std. } \\
\text { Deviation }\end{array}$ & $\begin{array}{l}\text { Std. } \\
\text { Error Mean }\end{array}$ & $\begin{array}{l}\text { Wilks' } \\
\text { Lambda }\end{array}$ & $\begin{array}{l}\text { p-value } \\
\begin{array}{l}\text { Clinical measurement } \\
\text { of canine }\end{array}\end{array}$ \\
& Males & 60 & 7.21 & 0.45 & 0.06 & 0.74 & 0.001 \\
& Females & 60 & 6.77 & 0.29 & 0.04 & & \\
\hline
\end{tabular}

Table 2. Measurement of accuracy of the study.

\begin{tabular}{llll}
\hline & \multicolumn{2}{c}{ Gender of the patient } \\
\cline { 2 - 4 } Percentage of accurate prediction & Females & Males & Total \\
& $76.7 \%$ & $68.3 \%$ & $72.5 \%$ \\
\hline Function at group centroids & -0.588 & 0.588 & $\begin{array}{l}\text { Classified as male if } D>0 \\
\text { Classified as female if } D<0\end{array}$ \\
\hline
\end{tabular}




\section{Discussion}

Teeth are the finest human remains that can be preserved for a longer period of time. Although many accurate techniques (DNA analysis) are available for sex determination, lack of facilities and cost factor become sabotage for their usage in developing countries like India. In such conditions teeth provide an excellent source, as they are easily available, robust in extreme environments and the procedure of sex determination is simple and economical.

Odontometrics is the study of tooth measurements which play a crucial role in anthropology as they were known to show significant dimorphism in gender. Canines were observed to show higher sexual dimorphism among all teeth. This can be attributed to many factors which include:

a) Influence of environmental factors and eating habits (6).

b) Evolutionary differences in the size of canines in males and females where the size of canines were related to threat of aggression in primates (7).

c) Genetic influence of $Y$ chromosome in determination of size of the canine (8).

d) Influence of steroid hormones on tooth size and shape (9).

Khangura has conducted a study among 100 dental students (50 males and 50 females). He found significant difference in the mesiodistal diameters of left and right canines in males. He also found higher sexual dimorphism in left side canines than right side (4). Similar results were also reported by Ayoub et al. and Kapila et al. $(3,5)$. Hence we included only left mandibular canines in order to eliminate discrepancy of canine measurements based on sides and to obtain the highest sexual dimorphism possible in the study.

Mandibular canine index $(\mathrm{MCl})$ is a regularly used method for determining sex using canine teeth. But Acharya et al. suggested that $\mathrm{MCl}$ has insignificant use in sex determination and its application has to be restricted or discontinued in forensic and anthropological sex predictions (10). Sherfudhin et al. compared $\mathrm{MCl}$ with $\mathrm{DCl}$ in his study, and concluded, $\mathrm{DCl}$ to be a better indicator for sex determination (11). Hence we confined our study to discriminant analysis for obtaining better results.

Discriminant equation is a statistical method used to classify individuals into groups on the basis of set of measurements. It is more commonly used in forensic studies for sex determination. Hence we used discriminant analysis in the present study to derive the discriminant canine equation. The $\mathrm{DCl}$ derived from this equation represents a value based on which the gender of the patient can be predicted. The results showed $76.7 \%$ accuracy in females, $68.3 \%$ accuracy in males and an overall accuracy of $72.5 \%$ in determining the gender using $\mathrm{DCl}$. The results in the present study were much higher when compared to the results of Hosmani et al. (1).

Many studies in the literature have proposed higher accuracy rate of sex determination using mandibular canine index, when compared to the present study $(12,13)$. But our results strictly support the use of $\mathrm{DCl}$ over $\mathrm{MCl}$ for better and reliable results. This can be attributed to the fact that $\mathrm{MCl}$ is a relative value obtained from the ratio of mesiodistal width of canine and inter - canine arch width, while $\mathrm{DCl}$ is an absolute measurement. Acharya et al. has explained this with an excellent example in his article, where he considered a male canine with $8 \mathrm{~mm}$ of mesiodistal width and $32 \mathrm{~mm}$ of inter-canine arch width, and a female canine with $6 \mathrm{~mm}$ of mesiodistal width and 24 $\mathrm{mm}$ of inter-canine arch width. Though the male dimensions were $33.33 \%$ larger than the female, $\mathrm{MCl}$ was interestingly the same in both the genders $(8 / 32$ $=6 / 24=0.25$ ) (10). Hence the degree of dimorphism also depends on the influence of parameters (mesiodistal width and inter canine arch width) over one another in $\mathrm{MCl}$. Therefore $\mathrm{DCl}$ has a definite advantage over $\mathrm{MCl}$ in sex determination.

The degree of sexual dimorphism in a given population varies according to their evolutionary change, genetic factors and ethnic background (1). Schield et al. observed higher sexual dimorphism in Ohio Caucasians and Australian aborigines than pima Indians and tristanite populations (14). Interestingly Acharya et al. found reverse sexual dimorphism (females showed larger teeth compared to males) in Nepalese population (15). These results conclude that individual discriminant analysis should be done based on the ethnic origin and separate discriminant equations must be derived for better and accurate sex determination.

Forensic odontology is an emerging field in countries like India. Hence a comprehensive database must be established using all the possible morphometric measurements of tooth and their accuracy or variations in degree of sex determination must be analyzed. The present study indicated that the $\mathrm{DCl}$ can produce reliable results and can be used as an adjunct tool along with other accepted procedures for sex determination.

\section{References}

1. Hosmani JV, Nayak RS, Kotrashetti VS, Pradeep S, Babji D. Reliability of Mandibular Canines as Indicators for Sexual Dichotomy. J Int Oral Health. 2013 Feb;5(1):1-7.

2. Yuwanati M, Karia A, Yuwanati M. Canine tooth dimorphism: An adjunct for establishing sex identity. J Forensic Dent Sci. 2012;4(2):80-3.

3. Ayoub F, Shamseddine L, Rifai M, Cassia A, Diab R, Zaarour I, et al. Mandibular Canine Dimorphism in Establishing Sex Identity in the Lebanese Population. Int $\mathrm{J}$ Dent [Internet]. 2014 [cited 2014 May 16];2014. Available from: http://www.ncbi.nlm.nih.gov/pmc/articles/PMC3941160/

4. Khangura RK, Sircar K, Singh S, Rastogi V. Sex determination using mesiodistal dimension of permanent maxillary incisors and canines. J Forensic Dent Sci. 2011;3(2):81-5.

5. Kapila R, Nagesh KS, lyengar AR, Mehkri S. Sexual Dimorphism in Human Mandibular Canines: A Radiomorphometric Study in South Indian Population. J Dent Res Dent Clin Dent Prospect. 2011;5(2):51-4.

6. Lew KK, Keng SB. Anterior crown dimensions and relationship 
in an ethnic Chinese population with normal occlusions. Aust Orthod J. 1991 Oct;12(2):105-9.

7. Osborne RH, Horowitz SL, De George FV. Genetic variation in tooth dimensions: a twin study of the permanent anterior teeth. Am J Hum Genet. 1958 Sep;10(3):350-6.

8. McLaren A. Sex determination. What makes a man a man? Nature. 1990 Jul 19;346(6281):216-7.

9. Garn SM, Lewis AB, Kerewsky RS. The relationship between sexual dimorphism in tooth size and body size as studied within families. Arch Oral Biol. 1967 Feb;12(2):299-301.

10. Acharya AB, Angadi PV, Prabhu S, Nagnur S. Validity of the mandibular canine index $(\mathrm{MCl})$ in sex prediction: Reassessment in an Indian sample. Forensic Sci Int. 2011;204 (1):e1-4.

11. Sherfudhin $\mathrm{H}$, Abdullah MA, Khan N. A cross-sectional study of canine dimorphism in establishing sex identity: comparison of two statistical methods. J Oral Rehab. 1996 23:627-31.

12. Nair P, Rao BB, Annigeri RG. A study of tooth size, symmetry and sexual dimorphism. J Forensic Med Toxicol. 1999;16:10-3.

13. Muller M, Lupipegurier L, Quatrehomme G, Bolla M. Odontometrical method useful in determining gender and dental alignment. Forensic Sci Int. 2001;121:194-7.

14. Schield ED, Altschuller A, Choi EY, Michaud M. Odontometric variation among American black, European and Mongoloid population. J Craniofac Genet Biol. 1990;10:7.

15. Acharya A, Mainali S. Univariate sex dimorphism in the Nepalese dentition and the use of discriminant functions in gender assessment. Forensic Sci Int. 2007;173:47-56. 